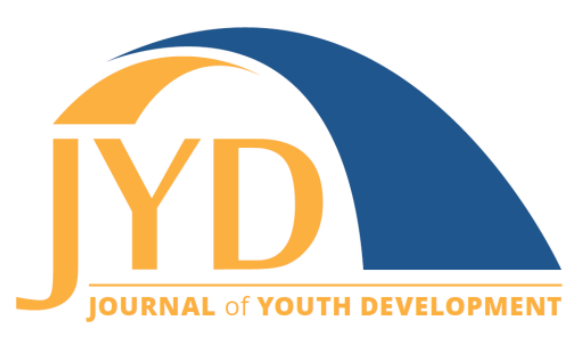

http://jyd. pitt. edu/ | Vol. 13 Issue 4 DOI 10.5195/jyd.2018.645 | ISSN 2325-4017 (online)

\title{
Parents' and Youths' Solicitation and Disclosure of Information in Today's Digital Age
}

\author{
Jessie H. Rudi \\ University of Minnesota \\ conne262@umn.edu \\ Jodi Dworkin \\ University of Minnesota \\ jdworkin@umn.edu
}

\begin{abstract}
Extensive research has identified parental monitoring to be a protective factor for youth. Parental monitoring includes parents' solicitation of information from their child and the child's voluntary disclosure of information. In today's digital society, parental monitoring can occur using technology, such as text messaging, email, and social networking sites. The current study describes parents' and youths' communication technology use explicitly to solicit and share information with each other in a sample of 56 parent-youth dyads from the same family (youth were 13 to 25 years old). We also examined associations between in-person parental monitoring, parental monitoring using technology, parental knowledge, and youth substance use initiation. Results revealed great variability in frequency of parental monitoring using technology, with a subgroup of parents and youth reporting doing these behaviors very frequently. Parental monitoring using technology was not associated with greater parental knowledge or youth substance use initiation after controlling for youth age group (adolescent or emerging adult) and gender composition of dyads. However, in-person communication between youth and parents remained an important variable and was positively associated with parental knowledge. Youth workers could empower parents to focus on in-person communication, and not rely solely on communication using technology.
\end{abstract}

Key words: parental monitoring, technology, substance initiation, parent-child communication

(c) $\mathrm{EY}_{\mathrm{EY}}$ New articles in this journal are licensed under a Creative Commons Attribution 4.0 License. This journal is published by the University Library System, University of Pittsburgh and is cosponsored by the University of Pittsburgh Press. The Journal of Youth Development is the official peer-reviewed publication of the National Association of Extension 4-H Agents and the National AfterSchool Association. 
Parental Monitoring Using Technology

\section{How Do Parents and Youth Solicit and Share Information in Today's Digital} Age?

Adolescent drug and alcohol use remains a pervasive and persistent problem with the potential for serious health and safety consequences for today's youth (National Institutes of Health, 2010). In $2017,16.6 \%$ of $12^{\text {th }}$ graders, $9.8 \%$ of $10^{\text {th }}$ graders, and $3.7 \%$ of eighth graders in the United States reported binge drinking (defined as having five drinks in a row) in the last two weeks (National Institute on Drug Abuse [NIDA], 2017). In addition, $37.1 \%$ of $12^{\text {th }}$ graders reported past-year use of marijuana (NIDA, 2017). In 2016, 20.2\% of U.S. high school students reported using any tobacco product, including electronic cigarettes, cigarettes, and cigars (Jamal et al., 2017). In addition to the prevalence of substance use among adolescents, their psychosocial adjustment is also a concern; recent reports find that one in five adolescents has a diagnosable mental health disorder (Murphey, Barry, \& Vaughn, 2013). It is essential that today's youth have the skills, resources, and healthy relationships needed to thrive.

A known protective factor for youth is parents' knowledge of youths' activities, whereabouts, and associations. Previous research has demonstrated that parental monitoring, or the process of obtaining knowledge of children's daily lives, involves parents' general limit-setting, solicitation of information from their children, and children's disclosure of that information (Kerr \& Stattin, 2000; Stattin \& Kerr, 2000). Today, parents and youth have access to communication technologies, such as text messaging and social networking websites like Facebook, that allow for communication to occur while parents and children are physically separated.

Despite extensive use of these technologies among parents and youth (Lenhart et al., 2015; Rudi, Dworkin, Walker, \& Doty, 2015), little is known about how parents use these technologies for monitoring (parental solicitation and child disclosure, specifically), and whether the use of technology for parental monitoring is related to parental knowledge or youths' substance use initiation. To better understand these relationships, the current study aimed to describe parental monitoring using technology in relation to in-person monitoring behaviors. In addition, we examined associations between monitoring behaviors, parental knowledge, and youth substance use.

\section{Theoretical Framework}

Efforts aiming to prevent problematic behaviors and promote positive youth development are excellent investment strategies for youth, families, and communities (Bogenschneider, 1996). 
Parental Monitoring Using Technology

Prevention theory focuses on minimizing risk factors while promoting protective factors for youth within various developmental systems (Kumpfer, 1999; Nation et al., 2003). These risk and protective factors can be targeted through prevention programming, policy, and other efforts to support positive youth development. According to prevention theory and extensive research on parenting and parent-child relationships, parental monitoring (leading to parental knowledge) and parent-child relationship quality are known protective factors against substance use and delinquent behaviors for youth (Dishion \& McMahon, 1998; Kumpfer, 1999). Exploring parental monitoring and the specific role communication technology use plays in parental monitoring is essential for informing prevention strategies and approaches.

\section{Conceptualizing Parental Monitoring}

Stattin and Kerr (2000) defined parental monitoring to encompass three ways parents actually obtain knowledge about their child's behavior: (a) through children's voluntary disclosure of information, (b) through parents' solicitation of information, and (c) parental control. Child disclosure refers to children's willingness to provide honest information to their parents (Stattin \& Kerr, 2000). Parental solicitation refers to parents' active efforts to obtain information from their children, such as asking what happened at school that day and where their child is going on a weekend evening. Parental control, as defined by Stattin and Kerr (2000), refers to parents' active efforts to control their adolescents' behaviors through the use of rules and restrictions, such as curfews and requiring permission before attending social activities. Together, parental solicitation and control describe parents' purposeful tracking and surveillance behaviors that can be considered monitoring activities. Parent behavior (solicitation of information from the adolescent and setting and enforcing limits) and adolescent behavior (disclosure of information) have been shown to account for a large amount of variance in parental knowledge of adolescents' activities and behaviors (up to 50\%, a substantial amount of variance for this field; Stattin \& Kerr, 2000).

Parental knowledge during adolescence has been studied extensively, and is a known protective factor against drug and alcohol use and other risky behaviors during adolescence (DiClemente et al., 2001; Waizenhofer, Buchanan, \& Jackson-Newsom, 2004). Adolescents whose parents know relatively more about their day-to-day life show lower levels of drug and alcohol use (DiClemente et al., 2001; Steinberg, 2001), delinquency, school problems, and depressed mood (Crouter \& Head, 2002). They also show higher levels of self-esteem and better school performance. Low levels of parental knowledge have been associated with high levels of 
Parental Monitoring Using Technology

adolescent problem behaviors, such as delinquency and substance use initiation (Crouter \& Head, 2002).

\section{Implications of Parental Monitoring for Substance Use}

Substance use during adolescence is associated with several short- and long-term health and social outcomes (NIDA, 2012). Fatalities involving alcohol consumption are responsible for over 5,000 adolescent deaths each year, all of which are preventable and include vehicle accidents, suicides, and other accidents and injuries (Hingson \& Kenkel, 2004). Substance use during adolescence also predicts substance use problems and negative outcomes in emerging adulthood and adulthood (e.g., Schulenberg, Maggs, \& O'Malley, 2003). By better understanding the associations between parental monitoring using technology and youth outcomes, researchers, scholars, and youth and family educators can begin to develop effective monitoring strategies for parents and youth in today's digital age.

\section{Parental Monitoring in Today's Digital Age}

Youth and their parents are active users of technology. Recent trends show that $92 \%$ of U.S. teens report going online daily, with $24 \%$ reporting that they go online "almost constantly" (Lenhart et al., 2015). In addition, the typical teen sends and receives at least 30 text messages each day (Lenhart et al., 2015). Compared to the general adult population, parents of adolescents are more likely to be Internet users (87\% versus 78\%; Lenhart et al., 2011). The majority of parents (91\%) of children ages 12 to17 own cell phones and $86 \%$ report text messaging (Lenhart et al., 2011). Recent research has found that over $90 \%$ of parents of adolescents reported using text messages and almost three-quarters reported using social networking sites specifically for the purpose of communicating with their children (Rudi et al., 2015). Despite these statistics, little is known about how parents and adolescents use technology to communicate with each other. Of research that does exist, most focuses on parental monitoring specifically of adolescents' online activity without attention to how technologies might be used specifically for staying connected (Lenhart, 2012; Rogers, Taylor, Cunning, Jones, \& Taylor, 2006).

Traditionally, parents solicited information from their adolescent by asking where they were going and with whom before their adolescent left the house, or asking what their adolescent did at school that day (Stattin \& Kerr, 2000), and adolescents disclosed this information in person. 


\section{Parental Monitoring Using Technology}

As a result of widespread access to and use of communication technologies (Lenhart, 2012; Lenhart et al., 2011; Madden, Lenhart, Duggan, Cortesi, \& Gasser, 2013), parents can now solicit information from adolescents and adolescents can disclose information to parents using technology, such as through text messaging and social networking sites like Facebook. The vast majority of previous research on parental monitoring has not distinguished the specific communication method used (in person or using technology) to obtain information nor has it considered the impact of communication method on parental knowledge or youth outcomes. To fully understand parental monitoring and its impact on youth outcomes in today's digital age, it is important to understand which communication methods may be more likely to lead to parental knowledge. In addition, researchers and educators should not assume that online communication operates similarly to in-person communication. This practical information can help parents effectively maintain their relationship with their youth during the teen years.

This exploratory study makes several key contributions to the field regarding our understanding of the relationship between parental monitoring and youth substance use initiation. Specifically, it explores a relatively new phenomenon occurring in families today, that is, the use of technology for parental monitoring. In addition, it provides information about the relationship between parental monitoring using technology and youth substance use initiation, bringing the field of parental monitoring into today's digitized world. The descriptive information provided by this research lays the foundation for future research to further examine how technology can be used as a tool to help parents effectively monitor their children.

\section{Research Questions and Hypotheses}

This study describes in-person parental monitoring and parental monitoring using technology. It also explores associations between parental monitoring using technology, parental knowledge, and youth substance use initiation in a sample of matched parent-youth dyads ( $N=56$ dyads).

\section{Research question}

How frequently do youth and parents report in-person parental monitoring and parental monitoring using technology (parental solicitation and child disclosure)? 


\section{Hypothesis 1}

Parental monitoring using technology will account for a significant amount of variance in parental knowledge above and beyond in-person parental monitoring, after controlling for youth age (adolescent or young adult), gender composition of the dyad (e.g., son-mother, daughterfather), parental trust/warmth, and parental control.

\section{Hypothesis 2}

Youth who report substance use initiation will report lower levels of in-person parental monitoring, parental monitoring using technology, and parental knowledge compared to youth who do not report substance use initiation.

\section{Methodology}

\section{Data Collection}

Parents of high school and college students (youth were 13 to25 years old) were recruited to participate in an online survey through Facebook and Amazon Mechanical Turk (MTurk). Given the study's focus on parents and youth during adolescence and young adulthood, recruitment was designed to capture youth in both developmental periods. Facebook advertisements targeting racially diverse parents of high school and college students were posted on Facebook from mid-April 2014 to early June 2014, resulting in seven of the parents included in the current study. Amazon's Mechanical Turk (MTurk; www.MTurk.com) is an open online marketplace for labor recruitment, compensation, and data collection. Previous research has shown MTurk to be a viable, cost-effective method for obtaining large samples to participate in self-report questionnaire research (Buhrmester, Kwang, \& Gosling, 2011; Dworkin, Hessel, Gliske, \& Rudi, 2016). Research comparing MTurk samples to standard Internet samples has shown that MTurk samples are slightly more diverse in age, geographic location, and race and ethnicity (Buhrmester et al., 2011).

Youth were recruited to participate in the research project via invitations from their parent who participated in the study. After parents entered their email address for the iPad mini and Amazon.com gift card drawing, a message appeared encouraging the parent to paste text about the online survey and the survey link into an email to their child. 


\section{Parental Monitoring Using Technology}

The survey was administered using Qualtrics, an online survey tool optimized for use on mobile devices such as smartphones and tablets, increasing accessibility for parents who do not own desktop computers or laptops. The institution's IRB approved all study procedures.

\section{Participants}

Included in the current study are parent-child dyads in which both parent and child resided in the United States ( $N=56$ dyads). Youth age ranged from 13 to 25 , with an average age of 17.54 years. All youth in the 13-25 year old age range were included in the study sample to allow for the consideration of communication processes and implications on parental knowledge during adolescence and young adulthood, two critical developmental periods. Further, including all youth helped ensure sufficient power for the planned analyses. For subsequent analyses, youth were divided into two groups: adolescents (13-17, 58.9\%) and young adults (18-25, $41.1 \%)$. Almost half of youth were female (46.4\%), and $75 \%$ of parents were female. Over one-third of dyads (39.3\%) were mother-daughter dyads, $26.8 \%$ were mother-son dyads, $16.1 \%$ were father-son dyads, and $7.1 \%$ were father-daughter dyads. Approximately twothirds $(66.1 \%)$ of youth were White, $12.5 \%$ were Black, $8.9 \%$ were Asian, and $5.4 \%$ were Hispanic. The majority of parents were White (69.6\%), 17.9\% were Black, 5.4\% were Asian, and $5.4 \%$ were Hispanic.

About one-third of parents (33.9\%) had a four-year college degree, and $14.3 \%$ had some postgraduate training. The majority of parents worked full-time (67.2\%) and $13.8 \%$ worked parttime. Half of parents $(51.7 \%)$ reported earning between $\$ 10,000$ and $\$ 50,000$ last year. The majority of parents were married $(67.9 \%), 14.3 \%$ were single, and $10.7 \%$ were divorced or separated. Over half of parents reported living in a suburban area (55.2\%), 24.1\% reported living in a rural area, and $19.0 \%$ reported living in an urban area (see Table 1 for more information about demographic characteristics of the sample).

\section{Measures}

Several of the measures included in the online survey used slider bars, a graphic rating scale that allows respondents to be more precise in how they answer questions by allowing choice in between scale options (for example, parents could choose to place the slider between "rarely" and "sometimes", rather than having to choose between the two options). Parents and youth reported on the same constructs. 
Journal of Youth Development | http://jyd.pitt.edu/ | Vol. 13 Issue 4 DOI 10.5195/jyd.2018.645

Parental Monitoring Using Technology

Table 1. Demographic Information About Study Sample ( $N=56$ Parent-Youth Dyads)

\begin{tabular}{|c|c|c|c|c|c|}
\hline \multicolumn{2}{|c|}{ Demographic characteristic } & \multicolumn{2}{|c|}{ Youth } & \multicolumn{2}{|c|}{ Parents } \\
\hline & & $n$ & $\%$ & $n$ & $\%$ \\
\hline \multirow[t]{5}{*}{ Age } & $13-17$ & 33 & 58.9 & -- & -- \\
\hline & $18-25$ & 23 & 41.1 & -- & -- \\
\hline & $25-34$ & -- & -- & 6 & 10.7 \\
\hline & $35-44$ & -- & -- & 28 & 50.0 \\
\hline & $45-55$ & -- & -- & 21 & 37.5 \\
\hline \multirow{6}{*}{$\begin{array}{l}\text { Race/ } \\
\text { ethnicity }\end{array}$} & American Indian or Alaska Native & 1 & 1.8 & 1 & 1.8 \\
\hline & Asian & 5 & 8.9 & 3 & 5.4 \\
\hline & Black & 7 & 12.5 & 10 & 17.9 \\
\hline & White & 37 & 66.1 & 39 & 69.6 \\
\hline & Hispanic & 3 & 5.4 & 3 & 5.4 \\
\hline & Mixed Race & 2 & 3.6 & 0 & 0.0 \\
\hline \multirow{9}{*}{$\begin{array}{l}\text { Education } \\
\text { level }\end{array}$} & $8^{\text {th }}-9^{\text {th }}$ grade & 11 & 19.6 & -- & -- \\
\hline & $10^{\text {th }}-12^{\text {th }}$ grade & 28 & 50.0 & -- & -- \\
\hline & $1^{\text {st-2 }} 2^{\text {nd }}$ year college & 12 & 21.4 & -- & -- \\
\hline & $3^{\text {rd }}-4^{\text {th }}$ year college & 5 & 8.9 & -- & -- \\
\hline & High School/GED & -- & -- & 5 & 8.9 \\
\hline & Tech/vocational school & -- & -- & 5 & 8.9 \\
\hline & Some college & -- & -- & 19 & 33.9 \\
\hline & College graduate & -- & -- & 19 & 33.9 \\
\hline & Post-graduate training & -- & -- & 8 & 14.3 \\
\hline \multirow[t]{6}{*}{ Income } & Less than $\$ 10,000$ & -- & -- & 2 & 3.4 \\
\hline & $\$ 10,000$-under $\$ 50,000$ & -- & -- & 30 & 51.7 \\
\hline & $\$ 50,000$-under $\$ 75,000$ & -- & -- & 10 & 17.2 \\
\hline & $\$ 75,000$-under $\$ 100,000$ & -- & -- & 9 & 15.5 \\
\hline & $\$ 100,000$ or more & -- & -- & 3 & 5.2 \\
\hline & Don't know or prefer not to answer & -- & -- & 3 & 5.2 \\
\hline \multirow{5}{*}{$\begin{array}{l}\text { Parents' } \\
\text { marital } \\
\text { status }\end{array}$} & Divorced or separated & 8 & 14.3 & 6 & 10.7 \\
\hline & Married & 34 & 60.7 & 38 & 67.9 \\
\hline & Living with partner & 2 & 3.6 & 2 & 3.6 \\
\hline & Single & -- & -- & 8 & 14.3 \\
\hline & Widowed & 3 & 5.4 & 2 & 3.6 \\
\hline
\end{tabular}




\section{Child Disclosure}

Youth were asked how often they tell the parent who referred them to participate in the study about different topics in person and using technology by responding to six total items (Kerr \& Stattin, 2000; Kerr, Stattin, \& Burk, 2010); three items about in-person child disclosure and three items about child disclosure using technology (e.g., "How often do you initiate a conversation with this parent about school (relationships with teachers, assignments, etc.)?" The slider labels were the same for the in-person and the using-technology questions: 0-1 = Almost never, 1-2 Rarely, 2-3 Sometimes, 3-4 Often, 4-5 Almost always. Parents answered the same questions about how often their child disclosed information in person and using technology. Scales were created by computing mean scores for in-person child disclosure (youth report $a=.68$; parent report $a=.67$ ), and child disclosure using technology (youth report $\mathrm{a}=.86$; parent report $\mathrm{a}=.88$ ).

\section{Parental Solicitation}

Youth reported how often the parent who referred them to complete the survey solicits information about different topics from them using ten total questions (Kerr \& Stattin, 2000; Kerr et al., 2010); five items asked about in-person parental solicitation and five items asked about parental solicitation using technology (e.g., "During the past month, how often has this parent started a conversation with you about your free time?"). Parents answered the same questions about how often they solicit information from their child. Scales were created by computing mean scores for in-person parental solicitation (youth report $a=.85$; parent report a $=.77$ ) and parental solicitation using technology (youth report $\mathrm{a}=.87$; parent report $\mathrm{a}=.89$ ).

\section{Parental Trust/Warmth}

Youth reported on trust and warmth in their relationships with their parents using 16 total questions; eight questions asked about their mother and eight questions asked about their father. The items were a combination of the trust subscale from the Inventory of Parent and Peer Attachment (IPPA; Armsden \& Greenberg, 1987; Greenberg \& Armsden, 2009) and items from the Parental Acceptance-Rejection Questionnaire (PARQ; Rohner, 2001). Response options were $1=$ Almost never or never true, $2=$ Not very often true, $3=$ Sometimes true, $4=$ Often true, and $5=$ Almost always or always true. Parents answered the same eight items about their relationship with their child who participated in the study. A scale for parental trust/warmth was created by computing the mean score across the eight items (youth report $a=.95$; parent report $\mathrm{a}=.82$ ). 
Parental Monitoring Using Technology

\section{Parental Control}

Youth reported how often the parent who referred them controls what the youth can do using five items (Kerr \& Stattin, 2000; Kerr et al., 2010; sample item: "Do you have to ask this parent before you can decide with your friends what you will do on a Saturday evening?"). The slider labels were the same as those for child disclosure and parental solicitation. Parents answered the same questions about their rules for their child who participated in the study. A scale for parental control was created by computing the mean score across the five items (youth report a $=.96$; parent report $\mathrm{a}=.91$ ).

\section{Parental Knowledge}

Youth reported how much each parent knows about their whereabouts, associations, and activities using 16 total questions (Kerr \& Stattin, 2000; Kerr et al., 2010); eight questions asked about how much their mother knows and eight questions asked about how much their father knows (e.g., "How often does [this parent] know which friends you hang out with during your free time?"). The slider labels were the same as those for child disclosure and parental solicitation. Parents answered the same questions about how much they know about their child who completed the survey. A scale for parental knowledge was created by computing the mean score across the eight items (youth report $a=.88$; parent report $a=.87$ ).

\section{Substance Use Initiation}

Youth and parents reported on youth initiation of cigarette, alcohol, and marijuana use using three items from the National Youth Risk Behaviors Survey (YRBS; Kann et al., 2013). All items were recoded to create one never/ever variable for each substance.

\section{Data Analysis Plan}

To answer our research question regarding how often parents and youth report in-person parental monitoring and parental monitoring using technology, frequency and descriptive analyses were computed (see Table 2).

To test our first hypothesis, that parental monitoring using technology will account for a significant amount of variance in parental knowledge, two hierarchical, cross-informant regression analyses were computed. One model included youths' report of independent variables with parents' report of parental knowledge as the dependent variable, and the second model included parents' report of independent variables with youths' report of parental knowledge as the dependent variable. 
Both cross-informant regressions included youth age, gender composition of the dyad, parental trust/warmth, parental control, in-person child disclosure, and in-person parental solicitation in the first step. The second step included child disclosure using technology and parental solicitation using technology.

Although stronger associations may be found in data from single informants, cross-informant analyses examining the effects of one informant's report on another's (in this case, youths' report of independent variables on parents' report of parental knowledge, and parents' report of independent variables on youths' report of parental knowledge), allow parent and youth behaviors and perceptions to be more accurately and reliably determined (Achenbach, McConaughy, \& Howell, 1987). Power analyses were computed to determine whether the sample size allowed for sufficient power to detect a medium effect size for step 2 of the model. Results showed that to find a medium effect size for the second step of the hierarchical multiple regression model (Cohen's $f^{2}=.20$; Cohen, 1988) with a desired statistical power level of .80, a sample size of 56 was required. Despite the small sample size of the current study, there was sufficient power to detect a medium effect size.

To test our second hypothesis, that youth who reported substance use initiation would report lower levels of in-person parental monitoring, parental monitoring using technology, and parental knowledge compared to youth who did not report substance use initiation, independent samples $t$-tests were computed comparing the two groups of youth.

Expectation maximization imputation was used to impute missing data for key study variables. Missing data ranged from zero cases missing data to four (7.1\%). Preliminary analyses were computed to examine differences in demographic characteristics between parents and youth missing any data and those with complete data. There were no differences in demographic characteristics of parents and youth with missing data and those with complete data. Missing value analysis (MVA) was computed in SPSS, and there were no significant patterns of missing data; data were assumed to be missing completely at random.

\section{Preliminary Analyses}

Given that parent-child communication and developmentally-appropriate parental monitoring differ depending on the developmental stage of the child (e.g., parenting an adolescent versus parenting a young adult; Arnett, 2000; Dishion \& McMahon, 1998), youth age group was 
Parental Monitoring Using Technology

included as a control variable in each model. Gender composition of parent-child dyads (i.e., mother-daughter, mother-son, father-daughter, father-son) has been associated with child disclosure, parental solicitation, and parental knowledge (Crouter \& Head, 2002; Waizenhofer et al., 2004), and was also included as a control variable in both models.

Preliminary analyses examining differences in key study variables by youth age group revealed

- Adolescents $(M=3.96)$ and their parents $(M=4.15)$ reported significantly more frequent child disclosure in person than young adults $(M=3.30)$ and their parents $(M=$ 3.57; $p<.01)$.

- Adolescents $(M=3.76)$ and their parents $(M=4.11)$ reported significantly higher levels of parental knowledge than young adults $(M=3.24)$ and their parents $(M=3.47 ; p$ $<.01)$.

- Adolescents $(M=4.11)$ and their parents $(M=4.34)$ reported significantly higher levels of parental control than young adults $(M=2.75)$ and their parents $(M=2.75 ; p$ $<.001)$.

Significant differences found by youth age group make sense given that the majority of young adults were living away from their parents and that the parenting needs of adolescents differ from those of young adults.

Preliminary analyses examining differences in key study variables by gender composition of dyads revealed

- Sons $(M=3.36)$ and their fathers $(M=3.15)$ reported significantly more frequent parental solicitation using technology than daughters $(M=1.98)$ and their fathers $(M=$ $1.28 ; p=.05)$.

- Mothers who reported on a daughter $(M=4.37)$ reported significantly more frequent child disclosure in person than fathers who reported on a daughter $(M=3.50 ; p<.05)$.

- Mothers who reported on a daughter $(M=4.56)$ reported significantly more parental control than mothers who reported on a son $(M=3.16 ; p=.05)$.

\section{Results}

\section{Describing Parents' and Youths'Monitoring Behaviors}

To answer our research question regarding frequency of in-person parental monitoring and parental monitoring using technology, frequency and descriptive analyses were computed. On 
Parental Monitoring Using Technology

average, youth and parents reported that the youth disclosed information in person "often" and that youth disclosed information using technology "sometimes" (see Table 2). None of the participants, youth or parent, reported that the youth "almost never" disclosed information in person (see Table 2).

On average, youth and parents reported that youth disclosed information using technology "sometimes" (see Table 2). A small proportion of youth (14.3\%) and parents (16.1\%) reported that the youth almost never disclosed information using technology (see Table 2).

On average, youth and parents reported that the parent solicited information in person "often" (see Table 2). Sixteen youths (28.57\%) and 13 parents (23.21\%) reported that the parent "almost always" solicited information in person (see Table 2 for additional information about frequency of in-person parental solicitation).

On average, youth and parents reported that the parent solicited information using technology "rarely" (see Table 2). Similar to child disclosure using technology, a small proportion of youth $(14.3 \%)$ and parents (19.6\%) reported that the parent almost never solicited information using technology (see Table 2 for more details). 
Table 2. Frequencies of Youth and Parent Report of Child Disclosure and Parental Solicitation in Person and Using Technology $(\mathbf{N}=56)$

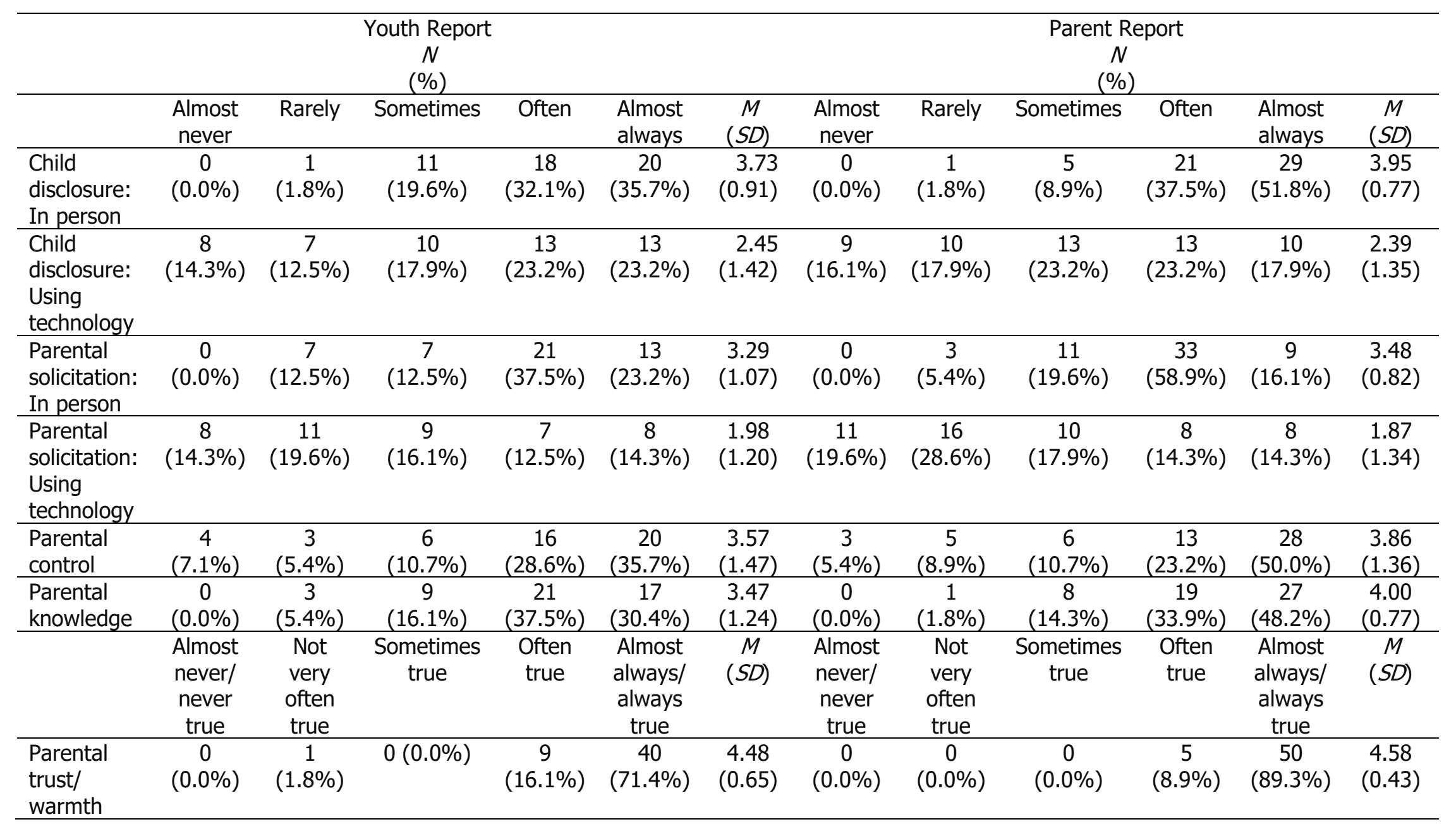




\section{Associations Between Parental Monitoring Using Technology and Parental Knowledge}

In analyses testing our first hypothesis, that parental monitoring using technology will account for a significant amount of variance in parental knowledge, the overall model with youths' report of parental knowledge as the dependent variable was significant, $F(6,43)=3.07, p=$ .01 (see Table 3). Independent variables included in the first step of the model accounted for $38 \%$ of the variance in youths' report of parental knowledge; youth age group and parents' report of in-person parental solicitation were the only statistically significant independent variables. The second step of the model accounted for only $3 \%$ of the variance and was not statistically significant.

The overall model with parents' report of parental knowledge as the dependent variable was significant, $F(6,43)=5.17, p<.001$ (see Table 3). Independent variables included in the first step of the model accounted for $52 \%$ of the variance in parents' report of parental knowledge; youth age group and youths' report of in-person child disclosure were the only significant independent variables. The second step of the model accounted for only $3 \%$ of the variance in parents' report of parental knowledge and was not statistically significant.

\section{Differences by Youth Substance Use Initiation}

Next, we tested our second hypothesis, that youth who report substance use initiation will report lower levels of in-person parental monitoring and parental monitoring using technology. Details about differences in parental monitoring by youth substance use initiation are reported in Table 4. Youth who had initiated cigarette use reported significantly lower levels of parental control (moderate effect size), and had parents who reported lower levels of parental control (moderate effect size) and lower levels of parental knowledge (moderate to large effect size) compared to youth who had not initiated cigarette use. Youth who had initiated alcohol use had parents who reported less frequent in-person parental solicitation (moderate effect size) and lower levels of parental knowledge (large effect size) compared to youth who reported not initiating alcohol use. No significant differences were found for child disclosure or parental solicitation using technology (see Table 4). 
Parental Monitoring Using Technology

\section{Discussion}

Extensive research has demonstrated the importance of parental knowledge of youths' whereabouts, associations, and activities as it relates to substance use initiation and delinquent behaviors (Crouter \& Head, 2002; Steinberg, 2001). In addition to acquiring this knowledge face-to-face, knowledge acquisition can now occur using technology, including via text message, email, Skype and FaceTime, and through the use of social networking sites. As such, information about how the use of technology may be a strategy for parents to obtain knowledge has direct implications for preventing youth substanceuse initiation and promoting positive youth development. Our results provide evidence to suggest that for both adolescents and young adults, in-person communication is still important. The lack of information in the current study regarding the context in which technology-mediated communication is happening may explain our lack of findings regarding technology-mediated monitoring.

\section{In-Person Communication Still Matters}

Parents' report of in-person parental solicitation was positively associated with youths' report of parental knowledge, and youths' report of in-person child disclosure was positively associated with parent report of parental knowledge. These findings are particularly striking given the small sample size and the use of a cross-informant design. Taken together, these results provide further evidence that despite the increase in use of technology for family communication, in-person communication remains an important aspect of parent-child relationships. Our results show that in-person monitoring contributes significantly to parental knowledge, which is a known protective factor for youth.

The lack of significant findings about child disclosure and parental solicitation using technology suggest that parents may still primarily obtain information about their youth via in-person communication. Alternatively, it could be that using technology to solicit information from adolescents is not necessarily related to better youth outcomes (e.g., Hessel, He, \& Dworkin, 2017). Perhaps technology use within the parent-child relationship serves a different purpose other than monitoring, or that parents are using technology for monitoring in different ways. Findings suggest that in-person child disclosure and parental solicitation each uniquely contribute to parents' and youths' perceptions of parental knowledge. The vast majority of research on parental monitoring finds child disclosure to be the most important factor contributing to parental knowledge, but these findings suggest that both disclosure and solicitation are important. 
Table 3. Hierarchical Multiple Regression Analyses Examining Variance in Youth and Parent Report of Parental Knowledge Accounted for by Youth and Parent Report of Independent Variables

\begin{tabular}{|c|c|c|c|c|c|c|c|c|c|c|c|}
\hline \multicolumn{6}{|c|}{ Youth report of parental knowledge } & \multicolumn{6}{|c|}{ Parent report of parental knowledge } \\
\hline & $B$ & SE B & $\beta$ & $t$ & $\Delta R^{2}$ & & $B$ & SE B & $\beta$ & $t$ & $\Delta R^{2}$ \\
\hline Step 1 & & & & & $.38 * *$ & Step 1 & & & & & $.52 * * *$ \\
\hline Youth age group ${ }^{a}$ & -0.25 & 0.36 & -0.13 & -0.71 & & Youth age group ${ }^{a}$ & -0.51 & 0.24 & -0.32 & $-2.13^{*}$ & \\
\hline Gender composition of dyad & 0.03 & 0.12 & 0.03 & 0.21 & & Gender composition of dyad & 0.28 & 0.09 & 0.44 & $3.17 * *$ & \\
\hline $\begin{array}{l}\text { Trust/warmth: } \\
\text { parent report }\end{array}$ & 0.11 & 0.36 & 0.05 & 0.31 & & $\begin{array}{l}\text { Trust/warmth: } \\
\text { youth report }\end{array}$ & -0.08 & 0.15 & -0.08 & -0.58 & \\
\hline Parental control: parent report & 0.06 & 0.12 & 0.09 & 0.49 & & Parental control: youth report & -0.13 & 0.09 & -0.23 & -1.35 & \\
\hline $\begin{array}{l}\text { In-person child disclosure: } \\
\text { parent report }\end{array}$ & 0.03 & 0.19 & 0.02 & 0.14 & & $\begin{array}{l}\text { In-person child disclosure: } \\
\text { youth report }\end{array}$ & 0.36 & 0.14 & 0.41 & $2.54 * *$ & \\
\hline $\begin{array}{l}\text { In-person parental } \\
\text { solicitation: parent report }\end{array}$ & 0.54 & 0.20 & 0.44 & $2.69 *$ & & $\begin{array}{l}\text { In-person parental solicitation: } \\
\text { youth report }\end{array}$ & 0.08 & 0.12 & 0.10 & 0.63 & \\
\hline \multicolumn{2}{|l|}{ Step 2} & & & & .03 & Step 2 & & & & & .03 \\
\hline $\begin{array}{l}\text { Child disclosure using } \\
\text { technology: } \\
\text { parent report }\end{array}$ & 0.11 & 0.12 & 0.17 & 0.91 & & $\begin{array}{l}\text { Child disclosure using } \\
\text { technology: } \\
\text { youth report }\end{array}$ & -0.02 & 0.09 & -0.04 & -0.24 & \\
\hline $\begin{array}{l}\text { Parental solicitation using } \\
\text { technology: parent report }\end{array}$ & 0.02 & 0.13 & 0.04 & 0.18 & & $\begin{array}{l}\text { Parental solicitation using } \\
\text { technology: youth report }\end{array}$ & 0.13 & 0.12 & 0.22 & 1.09 & \\
\hline Total $R^{2}$ & & & & & .41 & & & & & & .54 \\
\hline
\end{tabular}

Notes. aYouth age entered as dichotomous variable (adolescent or young adult). ${ }^{*} p<.05, * * p<.01$. 
Parental Monitoring Using Technology

\section{Importance of Context and Reason for Communication}

Youths' perceptions of the frequency of parental solicitation using technology may not be what leads to parental knowledge (Hessel et al., 2016). It could be that the contribution of parents' solicitation of information using technology to parental knowledge depends on the emotional climate in which parents are soliciting information from their child. In a warm, trusting relationship, asking for information via technology may be seen as a loving and caring behavior that youth respond to positively, while in a less warm, less trusting relationship, this behavior may be seen as an intrusive violation of privacy (Padilla-Walker, Nelson, Madsen, \& Barry, 2008). It could also be that parents hold off on soliciting information using technology until they are worried or concerned about their youth's associations, whereabouts, or activities. Parents also have the opportunity to be creative or sneaky in how they ask questions using technology, and their youth may not realize that they are being solicited for information. For example, parents may give false reasons for why they want to know certain information or could include pictures or emojis in their text messages to convey a certain kind of tone with their questions.

Alternatively, it could be that parents are not soliciting information via technology in the same ways as they do in person. Parental solicitation using technology may be appropriate for discussing certain topics, perhaps when the youth will be home or coordinating other logistics, while in-person parental solicitation may be more appropriate for discussing more emotional or difficult topics. Some research suggests that when parents and college students communicate for the purpose of checking in or to make plans, phone calling and text messaging are used frequently (Connell \& Dworkin, 2011). However, when parents and youth want to communicate about more serious or important topics, such as talking when upset, parents and college students communicate face-to-face (Connell \& Dworkin, 2011). Perhaps when parents really want important information, they ask their child in person, and technology is just a tool used for checking in about routines or schedules.

\section{Limitations and Future Research Directions}

Though this study begins to overcome some of the barriers to generating knowledge about parental monitoring in today's digital world, it is not without limitations. The sample size for the study was small, and there was not enough power to detect smaller effect sizes that may exist in the population. While the majority of youth in the sample were adolescents (59\% between 13-17 years old), over one-third were emerging adults. It is likely that parental monitoring serves different purposes and has different impacts on youth depending on the youth's developmental phase. While we included youth age as a control variable in our regression 
Parental Monitoring Using Technology

analyses, it is important to better understand how youth and parents are using technology for parental monitoring. Future research needs to use larger sample sizes and be intentional in including youth of particular ages.

This study employed a cross-sectional study design; therefore, it is impossible to determine the direction of effects, or whether bidirectional effects are occurring between parents and youth. Are parents proactively parenting children or is parenting a reaction to what children are doing? Longitudinal study designs and advanced statistical methods need to be employed to tease out these possibilities.

The findings from the current study lay the foundation for future research in parents' and youths' use of technology for sharing information. How youth manage their information is a complex process (e.g., Finkenauer, Engels, \& Meeus, 2002). Many factors not included in the current study likely affect technology-mediated communication, such as how youth manage private information in general and whether they keep secrets from parents. Future research could examine how youth use technology to manage information and keep particular types of information private from parents. Research has also shown that how parents react to youth disclosure of information is related to whether youth will disclose information in the future (Kerr \& Stattin, 2003; Tilton-Weaver et al., 2010). Examining parents' emotional reactions to youths' disclosure of information via technology, and also youths' emotional reaction to parents' solicitation of information via technology, would provide additional information about this complex process. Parental connectedness is a critical protective factor for youth, and further understanding how technology impacts connectedness is an important direction for future research.

Parents and youth were recruited to participate in this study using online recruitment methods, and therefore the sample includes youth and parents who are already actively online and likely comfortable using technology. The majority of the parent participants found the survey through MTurk. While these online methods resulted in a sample of matched parent-youth dyads, the parents who were recruited via MTurk were guaranteed a small sum of money as compensation. Although compensation was small, there may be issues related to parents' motivation, privacy while completing the online survey, and parents' attention span and effort while completing the survey. 
Parental Monitoring Using Technology

\section{Implications for Youth Workers}

For youth workers to effectively support positive youth development, they must understand the societal changes (i.e., increasing technology use among youth) and other systems changes (i.e., relationships with parents and other family members) that influence the youth they serve. The primary goal of many youth programs is to "stack the deck" in favor of youths' positive development, by increasing or supporting protective factors while decreasing or minimizing risk factors.

This study identified in-person communication with parents as a protective factor. Youth workers could empower both youth and their parents to continue regular in-person communication. It is also important for youth workers to share with parents that it is important to not rely solely on technological devices for communication. In addition, this information can be included in prevention programming and resources for parents, reminding them that despite their child's frequent use of technology for communication with peers, in-person family communication is still important for today's youth. It could be that in-person communication, both parents' solicitation and youths' disclosure, contribute to a warmer and/or more trusting parent-child relationship, as well as contribute to increased parental knowledge, which are known protective factors for youth.

Much research has shown child disclosure to be the primary driver of parental knowledge. However, in the current study, we found parents' solicitation of information to also significantly contribute to parental knowledge. This is an important message for parents in today's digital world. While adolescents and young adults may be very tuned in to their technological devices and prefer technology-mediated communication for connection with peers (Anderson \& Jiang, 2018), parents' inquiring about their children's lives in person still plays an important role in both the prevention of risk behaviors and the promotion of positive behaviors. This is a critical message for parents to receive both through written and online resources and programming to empower them to continue to reach out to their adolescent and young adult children in person.

\section{Conclusion}

The current exploratory and descriptive study has specific implications for parents and practitioners who work with parents and families. Results of this study show that more communication and more technology use to monitor or connect with youth is not necessarily 
Parental Monitoring Using Technology

better, and low technology use is not necessarily worse. Alternatively, technology should be thought of as a tool for parents and youth to check in, and this checking in keeps parents and youth on the same page about routines and rules and keeps lines of communication open.

\section{References}

Achenbach, T. M., McConaughy, S. H., \& Howell, C. T. (1987). Child/adolescent behavioral and emotional problems: Implications of cross-informant correlations for situational specificity. Psychological Bulletin, 101(2), 213-232. doi:10.1037/0033-2909.101.2.213

Anderson, M., \& Jiang, J. (2018). Teens, social media \& technology 2018. Retrieved from Pew Research Center website: http://www.pewinternet.org/2018/05/31/teens-social-media-technology-2018/

Armsden, G. C., \& Greenberg, M. T. (1987). The inventory of parent and peer attachment: Individual differences and their relationship to psychological well-being in adolescence. Journal of Youth and Adolescence, 16(5), 427-454. doi:10.1007/BF02202939

Arnett, J. J. (2000). Emerging adulthood: A theory of development from the late teens through the twenties. American Psychologist, 55(5), 469-480. doi:10.1037/0003-066X.55.5.469

Bogenschneider, K. (1996). An ecological risk/protective theory for building prevention programs, policies, and community capacity to support youth. Family Relations, 45(2), 127-138.

Buhrmester, M., Kwang, T., \& Gosling, S. D. (2011). Amazon's mechanical Turk: A new source of inexpensive, yet high-quality, data? Perspectives on Psychological Science, 6(1), 3-5. doi:10.1177/1745691610393980

Cohen, J. (1988). Statistical power analysis for the behavioral sciences ( $2^{\text {nd }}$ ed.). Hillsdale, NJ: Lawrence Earlbaum Associates.

Connell, J., \& Dworkin, J. (2011). College students' information and communications technology (ICT) use with parents. Association of Higher Education Parent/Family Program Professionals Journal, 2(2), 2-16.

Crouter, A. C., \& Head, M. R. (2002). Parental monitoring and knowledge of children. In M. H. Bornstein (Ed.), Handbook of Parenting: Vol. 3. Being and becoming a parent ( $2^{\text {nd }}$ ed. pp. 461-483). Mahwah, NJ: Lawrence Erlbaum.

DiClemente, R. J., Wingood, G. M., Crosby, R., Sionean, C., Cobb, B. K., Harrington, K., . . \& Oh, M. K. (2001). Parental monitoring: Association with adolescents' risk behaviors. Pediatrics, 1076), 1363-1368.

Dishion, T. J., \& McMahon, R. J. (1998). Parental monitoring and the prevention of child and adolescent problem behavior: A conceptual and empirical formulation. Clinical Child and Family Psychology Review, 1(1), 61-75. doi:10.1023/A:1021800432380 
Dworkin, J., Hessel, H., Gliske, K., \& Rudi, J. H. (2016). A comparison of three online recruitment strategies for engaging parents. Family Relations, 65(4), 550-561. doi:10.1111/fare.12206

Finkenauer, C., Engels, R. C. M. E., \& Meeus, W. (2002). Keeping secrets from parents: Advantages and disadvantages of secrecy in adolescence. Journal of Youth and Adolescence, 31(2), 123-136. doi:10.1023/A:101406992

Greenberg, M. T., \& Armsden, G. (2009, August). Inventory of parent and peer attachment (IPPA). Retrieved from https://emdrtherapyvolusia.com/wpcontent/uploads/2016/12/Attachment_Inventory-Article.pdf

Hessel, H., He, Y., \& Dworkin, J. (2017). Paternal monitoring: The relationship between online and inperson solicitation and youth outcomes. Journal of Youth \& Adolescence, 46(2), 288-299. doi:10.1007/s10964-016-0490-6

Hingson, R., \& Kenkel, D. (2004). Social, health, and economic consequences of underage drinking. Washington, DC: The National Academies Press.

Jamal, A., Gentzke, A., Hu, S. S., Cullen, K. A., Apelberg, B. J., Homa, D. M., \& King, B. A. (2017). Tobacco use among middle and high school students - United States, 2011-2016. Morbidity \& Mortality Weekly Report, 66, 597-603. doi:10.15585/mmwr.mm6623a1

Kann, L., Kinchen, S., Shanklin, S. L., Flint, K. H., Hawkins, J., Harris, W. A. ... Zaza, S. (2013). Youth risk behavior surveillance - United States, 2013. Morbidity and Mortality Weekly Report, 63(4). Retrieved from http://www.cdc.gov/mmwr/pdf/ss/ss6304.pdf

Kerr, M., \& Stattin, H. (2000). What parents know, how they know it, and several forms of adolescent adjustment: Further support for a reinterpretation of monitoring. Developmental Psychology, 36(3), 366-380. doi:10.1037/0012-1649.36.3.366

Kerr, M., \& Stattin, H. (2003). Parenting of adolescents: Action or reaction? In A. C. Crouter \& A. Booth (Eds.), Children's influence on family dynamics: The neglected side of family relationships (pp. 121-151). Mahwah, New Jersey: Lawrence Erlbaum Associates.

Kerr, M., Stattin, H., \& Burk, W. J. (2010). A reinterpretation of parental monitoring in longitudinal perspective. Journal of Research on Adolescence, 20(1), 39-64. doi:10.1111/j.15327795.2009.00623.x

Kumpfer, K. L. (1999). Factors and processes contributing to resilience: The resilience framework. In Glantz, M. D., Johnson, J. L., (Eds.), Resilience and Development: Positive Life Adaption (pp. 179-224). New York, NY: Kluwer Academic.

Lenhart, A. (2012). Teens, smartphones, \& texting. Retrieved from Pew Internet \& American Life Project website: http://www.pewinternet.org/ /media//Files/Reports/2012/PIP_Teens_Smartphones_and_Texting .pdf 
Parental Monitoring Using Technology

Lenhart, A., Duggan, M., Perrin, A., Stepler, R., Rainie, L., \& Parker, K. (2015). Teens, social media, \& technology overview 2015: Smartphones facilitate shifts in communication landscape for teens. Retrieved from Pew Research Center website: http://www.pewinternet.org/2015/04/09/teenssocial-media-technology-2015/

Lenhart, A., Madden, M., Smith, A., Purcell, K., Zickuhr, K., \& Rainie, L. (2011). Teens, kindness and cruelty on social network sites. Retrieved from Pew Research Center website: http://www.pewinternet.org/2011/11/09/teens-kindness-and-cruelty-on-social-network-sites/

Madden, M., Lenhart, A., Duggan, M., Coresti, S., \& Gasser, U. (2013). Teens and technology 2013. Pew Research Internet Project. Retrieved from http://www.pewinternet.org/2013/03/13/teens-andtechnology-2013/

Murphey, D., Barry, M., \& Vaughn, B. (2013). Mental health disorders. Child Trends, 1, 1-10. Retrieved from https://www.childtrends.org/wp-content/uploads/2013/03/Child_Trends2013_01_01_AHH_MentalDisordersl.pdf

Nation, M., Crusto, C., Wandersman, A., Kumpfer, K. L., Seybolt, D., Morrissey-Kane, E., \& Davino, K. (2003). What works in prevention: Principles of effective prevention programs. American Psychologist, 58(6/7), 449-456. doi:10.1037/0003-066X.58.6-7.449

National Institute on Drug Abuse (2017). Monitoring the Future 2017 Survey Results. Retrieved from https://www.drugabuse.gov/related-topics/trends-statistics/infographics/monitoring-future-2017survey-results

National Institutes of Health (2010). Underage drinking fact sheet. Retrieved from http://report.nih.gov/nihfactsheets/Pdfs/UnderageDrinking(NIAAA).pdf

Padilla-Walker, L. M., Nelson, L. J., Madsen, S. D., \& Barry, C. M. (2008). The role of perceived parental knowledge on emerging adults' risk behaviors. Journal of Youth and Adolescence, 37, 347-359. doi:10.1007/s10964-007-9268-1

Rogers, M. C., Taylor, B., Cunning, D., Jones, M., \& Taylor, K. (2006). Parental restrictions on adolescent internet use. Pediatrics, 118(4), 1804-1805.

Rohner, R. P. (2001). Parental acceptance-rejection bibliography. Retrieved from http://vm.uconn.edu rohner.

Rudi, J., Dworkin, J., Walker, S., \& Doty, J. (2015). Parents' use of information and communications technologies for family communication: Differences by age of children. Information, Communication \& Society, 18(1), 78-93. doi:10.1080/1369118X.2014.934390

Schulenberg, J. E., Maggs, J. L., \& O'Malley, P. M. (2003). How and why the understanding of developmental continuity and discontinuity is important. In J.T. Mortimer \& M. J. Shanahan (Eds.), Handbook of the life course (pp. 413-416). New York, NY: Plenum Press.

Stattin, H., \& Kerr, M. (2000). Parental monitoring: A reinterpretation. Child Development, 71(4), 10721085. 
Journal of Youth Development | http://jyd.pitt.edu/ | Vol. 13 Issue 4 DOI 10.5195/jyd.2018.645

Parental Monitoring Using Technology

Steinberg, L. (2001). We know some things: Parent-adolescent relationships in retrospect and prospect. Journal of Research on Adolescence, 11(1), 1-19. doi:10.1111/1532-7795.00001

Tilton-Weaver, L., Kerr, M., Pakalniskeine, V., Tokic, A., Salihovic, S., \& Stattin, H. (2010). Open up or close down: How do parental reactions affect youth information management? Journal of Adolescence, 33, 333-346. doi:10.1016/j.adolescence.2009.07.011

Waizenhofer, R. N., Buchanan, C. M., \& Jackson-Newsom, J. (2004). Mothers' and fathers' knowledge of adolescents' daily activities: Its sources and its links with adolescent adjustment. Journal of Family Psychology, 18(2), 348-360. doi:10.1037/0893-3200.18.2.348 